\title{
Variabilidade genética de Phakopsora pachyrhizi avaliada por meio de marcadores microssatélites
}

\author{
Nely Norder Tschurtschenthaler( ${ }^{(1)}$, Elisa Serra Negra Vieira ${ }^{(2)}$, Tatiane Dalla Nora( ${ }^{(3)}$ e Ivan Schuster ${ }^{(3)}$ \\ (1)Universidade Paranaense, Caixa Postal 224, CEP 87502-210 Umuarama, PR. E-mail: nelytschuck@gmail.com (2)Embrapa Florestas, Caixa \\ Postal 319, CEP 83411-000 Colombo, PR. E-mail: elisa@cnpf.embrapa.br ${ }^{(3)}$ Cooperativa Central de Pesquisa Agrícola, Caixa Postal 301, \\ CEP 85813-450 Cascavel, PR. E-mail: tatianedn@coodetec.com.br, ivan@coodetec.com.br
}

Resumo - O objetivo deste trabalho foi avaliar a variabilidade genética da ferrugem-asiática-da-soja no Brasil, com uso de marcadores microssatélites. Populações de esporos de Phakopsora pachyrhizi coletadas nas regiões Sul, Sudeste e Centro Oeste do país foram submetidas à análise de variabilidade genética, avaliada por meio de marcadores microssatélites específicos para o fungo. Foram coletadas, também, populações de fungo em diversas variedades de soja em uma mesma localidade, incluindo populações com lesão "reddish-brown" (RB). Entre essas populações, não houve variabilidade. Tecidos com lesões RB não apresentaram esporos do fungo e não amplificaram com os marcadores específicos para $P$. pachyrhizi. A variabilidade genética entre as populações coletadas nas três regiões variou de 0 a 0,36 . Observou-se tendência de agrupamento das populações da região Sul e Centro Oeste do Brasil em grupos diferentes. A existência de variabilidade genética em populações de $P$. pachyrhizi é um indicativo de que a resistência genética vertical, conferida por genes únicos, é uma estratégia de risco para os programas de melhoramento genético que visam a resistência à ferrugem-asiática-da-soja no Brasil.

Termos para indexação: Glycine max, diversidade genética, ferrugem-asiática-da-soja, resistência genética, resistência vertical, SSR.

\section{Genetic variability of Phakopsora pachyrhizi accessed by microsatellite markers}

\begin{abstract}
The objective of this work was to evaluate the genetic variability of Asian soybean rust in Brazil using microsatellite markers. Samples of Phakopsora pachyrhizi spores collected in the Southern, Southeastern, and Central West regions of Brazil were subjected to analysis of genetic variability, accessed with microsatellite markers specific for the fungus. Spores of the fungus were also collected in several soybean varieties in a same locality, including samples with reddish-brown (RB) lesions. Among these samples, there was no variability. Tissues with RB lesions did not contain spores of the fungus and did not amplify with the specific markers for $P$. pachyrhizi. Genetic variability among samples collected in the three regions ranged from 0 to 0.36 . A tendency to cluster samples of the Southern and Central West regions of Brazil in different groups was observed. The existence of genetic variability in P. pachyrhizi spore populations indicates that vertical genetic resistance, provided by single genes, is a risky strategy for soybean breeding programs that aim resistance to Asian soybean rust.
\end{abstract}

Index terms: Glycine max, genetic diversity, Asian soybean rust, genetic resistance, vertical resistance, SSR.

\section{Introdução}

A ferrugem-asiática-da-soja, causada pelo fungo Phakopsora pachyrhizi Syd \& P. Syd, tem causado grandes prejuízos aos produtores brasileiros de soja [Glycine max (L.) Merr.]. Relatada no país desde 2002 (Schneider et al., 2005), a doença já causou danos que chegaram a 100\% em áreas não protegidas (Tecnologias de produção de soja, 2003), tendo-se dispersado por praticamente toda a área de cultivo no Brasil (Andrade et al., 2002).
Cinco genes de resistência à ferrugem-asiáticada-soja foram identificados em soja: Rppl (Cheng \& Chan, 1968; Hidayat \& Somaatmadja, 1977; McLean \& Byth, 1980; Hartwig \& Bromfield, 1982); Rpp2(Hidayat \& Somaatmadja, 1977); Rpp3 (Singh \& Thapliyal, 1977; Bromfield \& Hartwig, 1980); Rpp4 (Hartwig, 1985); e Rpp5 (Garcia et al., 2008). Foi constatado que o gene Rppl confere resposta imune da soja ao patógeno, pois, após a inoculação de certos isolados, as plantas não apresentaram sintomas visíveis (Miles et al., 2006). A resistência conferida pelos genes Rpp2 
a Rpp5 limita o crescimento e a esporulação do fungo, por meio de reação de hipersensibilidade que provoca lesão marrom-avermelhada visível, descrita como "reddish-brown" (RB) (Bonde et al., 2006; Garcia et al., 2008). A interação entre a ferrugem-asiática-da-soja e as plantas suscetíveis resulta em lesões de coloração bronzeada denominadas “Tan" (Bromfield \& Hartwig, 1980; Bromfield, 1984; Miles et al., 2006).

Diversos trabalhos relatam a existência de variabilidade genética em populações de $P$. pachyrhizi (Sinclair \& Hartman, 1999; Yamaoka et al., 2002; Bonde et al., 2006; Freire et al., 2008). As fontes identificadas de resistência, no entanto, são todas específicas a determinados isolados do fungo (Bonde et al., 2006). Yamaoka et al. (2002) identificaram 18 raças patogênicas de $P$. pachyrhizi no Japão, em isolados coletados em Pueraria lobata e G. soja. Nove raças foram identificadas em plantas de G. max.

No Brasil, na safra 2008/2009, as fontes de resistência contendo o gene Rppl ('PI200492' e 'Tainung-4') e Rpp3 ('PI462312') apresentaram-se suscetíveis a 100\% das populações de $P$. pachyrhizi testadas. As linhagens PI23097 e PI41725, que contêm o gene Rpp2, foram suscetíveis em 48,85 e 71,4\% dos locais de teste, respectivamente. PI459025, que contém o gene Rpp4, foi suscetível em $57,14 \%$ dos casos. Já a cultivar Shira Nui, com o gene $R p p 5$, apresentou resistência a $85,7 \%$ das populações testadas e resistência intermediária a outras 12,5\% (Soares et al., 2009).

Na Argentina e no Paraguai, na safra 2007/2008, as fontes de resistência que continham o gene Rpp 1 ('PI200492' e 'Tainung-4') apresentaram resistência em $12,5 \%$ dos casos, e a fonte de resistência com o gene Rpp3 ('PI462312') foi resistente em 20\% dos casos. Fontes de resistência contendo os genes Rpp2 ('PI23097' e 'PI41725'), Rpp4 ('PI459025') e Rpp5 ('Shira Nui') foram resistentes em 28,6, 60 e 57,1\% dos casos, respectivamente (Soares et al., 2009).

O conhecimento da variabilidade genética existente no patógeno é importante para que os programas de melhoramento genético possam realizar seu planejamento estratégico, uma vez que a probabilidade de quebra de resistência, quando variedades contendo apenas um gene de resistência vertical são desenvolvidas, é maior na medida em que a variabilidade do patógeno aumenta.

O objetivo deste trabalho foi avaliar a variabilidade genética da ferrugem-asiática-da-soja no Brasil, com uso de marcadores moleculares microssatélites.

\section{Material e Métodos}

Para avaliar a variabilidade do fungo entre as regiões de cultivo de soja, foram analisadas dez populações do fungo $P$. pachyrhizi, coletadas em folhas de plantas de soja em diferentes localidades do Brasil (Tabela 1). Nove populações foram coletadas em fevereiro de 2009 e uma em fevereiro de 2010.

Para avaliar a variabilidade do fungo em um mesmo ambiente, outras dez populações foram coletadas em Cascavel, PR, em fevereiro de 2010, em parcelas experimentais de dez genótipos diferentes, plantadas lado a lado. Seis dessas populações foram formadas de esporos, e quatro foram compostas de amostras de tecidos contendo lesões RB, coletadas em plantas resistentes, na expectativa de encontrar esporos nessas folhas (Tabela 2).

A extração de DNA foi realizada conforme Roeder \& Broda (1987), tendo-se utilizado de 240 a $300 \mathrm{mg}$

Tabela 1. Identificação das populações de esporos de Phakopsora pachyrhizi, coletadas em fevereiro de 2009 e de 2010, sobre diferentes cultivares de soja, utilizadas na análise de diversidade genética.

\begin{tabular}{lcccc}
\hline Amostra & Local da coleta & Estado & Ano & Cultivar \\
\hline Pp-PMT & Palmital & SP & 2009 & IAS-5 \\
Pp-SMPQ & São Miguel do Passo Quatro & MG & 2009 & Conquista \\
Pp-RVE & Rio Verde & GO & 2009 & Conquista \\
Pp-CMO & Campo Mourão & PR & 2009 & IAS-5 \\
Pp-PPO & Ponta Porã & MS & 2009 & Conquista \\
Pp-SRO & Santa Rosa & RS & 2009 & IAS-5 \\
Pp-CVL1 & Cascavel & PR & 2009 & IAS-5 \\
Pp-CAL & Conceição das Alagoas & MG & 2009 & Conquista \\
Pp-GPV & Guarapuava & PR & 2009 & Conquista \\
Pp-CVL2 & Cascavel & PR & 2010 & IAS-5 \\
\hline
\end{tabular}

Tabela 2. Populações de esporos e de lesões "reddish-brown" (RB) de Phakopsora pachyrhizi coletadas em fevereiro de 2010, em Cascavel, PR, sobre diferentes cultivares de soja.

\begin{tabular}{lcc}
\hline Amostra & Tipo de amostra & Cultivar \\
\hline Pp-PI230970 & Lesão RB & PI 230970 \\
Pp-PI 200492 & Lesão RB & PI 200492 \\
Pp-BRS MS Bacuri & Esporos & BRS MS Bacuri \\
Pp-BRS 134 & Esporos & BRS 134 \\
Pp-IAC 1 & Esporos & IAC 1 \\
Pp-CD 208 & Esporos & CD 208 \\
Pp-FT 17 & Esporos & FT 17 \\
Pp-FT 2 & Esporos & FT 2 \\
Pp-PI 462312 & Lesão RB & PI 462312 \\
Pp-PI 459025 & Lesão RB & PI 459025 \\
\hline
\end{tabular}


de micélios do fungo. As reações de amplificação foram realizadas em volume total de $20 \mu \mathrm{L}$, contendo $10 \mathrm{mmol} \mathrm{L}^{-1}$ de Tris- $\mathrm{HCl}(\mathrm{pH} 8,3), 1,5 \mathrm{mmol} \mathrm{L}^{-1} \mathrm{de}_{\mathrm{MgCl}_{2}}$, $0,1 \mu \mathrm{mol} \mathrm{L}{ }^{-1}$ de dNTP, $30 \mathrm{ng}$ de DNA e uma unidade da enzima Taq DNA polimerase. As amplificações foram realizadas em termociclador programado para etapa inicial de desnaturação a $95^{\circ} \mathrm{C}$, por $3 \mathrm{~min}$, seguida de 35 ciclos a $94^{\circ} \mathrm{C}$, por $30 \mathrm{~s}$, com temperatura de anelamento de $55^{\circ} \mathrm{C}$, e fase final de extensão a $72^{\circ} \mathrm{C}$, por $10 \mathrm{~min}$. Os fragmentos amplificados foram separados por eletroforese em gel de agarose com synergel, contendo brometo de etídio e tampão TBE 1X (90 $\mathrm{mmol} \mathrm{L}^{-1}$ Tris-Borato, 2,0 $\mathrm{mmol} \mathrm{L}^{-1}$ EDTA), e fotografados sob luz ultravioleta em equipamento de foto documentação.

Para amplificação dos locos "simple sequence repeats" (SSR) do fungo $P$. pachyrhizi, foram utilizados 17 pares de iniciadores (Tabela 3), descritos por Anderson et al. (2008).

A dissimilaridade genética entre os acessos foi avaliada com uso do complemento do índice de similaridade para dados codominantes e multialélicos. O índice de similaridade foi obtido pela divisão do total de alelos comuns pelo número total de alelos avaliados em cada indivíduo.

A análise de agrupamento foi realizada pelo método das médias aritméticas não ponderadas (UPGMA).
As análises de dissimilaridade genética foram realizadas com auxílio do programa Genes (Cruz, 2001), e a análise de agrupamento foi realizada com auxílio do programa Statistica (StatSoft, 1999). A correlação cofenética entre os dados originais de distância e as distâncias obtidas a partir do dendrograma foram calculadas com base no coeficiente de correlação simples.

\section{Resultados e Discussão}

A tentativa de amplificação do DNA das dez populações de esporos coletadas de genótipos cultivados lado a lado em Cascavel, PR (Tabela 2), com uso dos marcadores microssatélites específicos para $P$. pachyrhizi, amplificou apenas as amostras obtidas dos esporos (Figura 1). As amostras obtidas dos tecidos contendo lesões RB não amplificaram com nenhum dos iniciadores microssatélites utilizados. A eventual presença de esporos de $P$. pachyrhizi em lesões $\mathrm{RB}$, relativamente comum em avaliações de campo, deve ser decorrente da infecção da planta por diferentes patótipos ou raças do patógeno, em que a planta desenvolve a reação de hipersensibilidade (RB) para um determinado patótipo, mas não para outro, o que resultaria na esporulação. Na coleta realizada, não havia patótipos capazes de esporular nas plantas resistentes utilizadas.

Tabela 3. Sequência dos iniciadores de microssatélites utilizados para amplificação das amostras de DNA de Phakopsora pachyrhizi.

\begin{tabular}{lcc}
\hline Iniciador & Fita senso (sequencia 5'-3') & Fita antissenso (sequencia 5'-3') \\
\hline PP003 & CTAGGTTCCAAGCTGTATTTC & CCTCTGTCCCAAACATAAGC \\
PP004 & ACTGTTCGGTTCGGTTTCAG & ACTGTTCGGTTCGTTTCAG \\
PP006 & ACCCTGCCACTGGTAAGAGA & CTTGGTTAAATGCCAAGCTTG \\
PP007 & CCTAGACTGTCAGGGTGAGAG & GGTTGATGTTAAGATGGGTTGG \\
PP008 & GTAGCTTCTAATCTCAGGCGTC & GAACCTGTTCGGGCTGCTTTAGG \\
PP009 & GGTACTGTATGACCCTGCCTG & GGACTCTAGAACTGCACTAG \\
PP010 & GGCAGGTGATTCGTAGAGTCTAC & CTGAGTGAAATCACGCTGAGA \\
PP011 & GAGTCAGCCTAAGCTCAGCCAC & GACCCTTGTGACAGCTGATTG \\
PP012 & GTTGCCAAAAAGTGGGGTGAG 014 & TGTAGCCCACCTTGAATCAG \\
PP016 & CCATCAGAGTTGTTGGCTCTC & CAGCGATCAGGTTCAGAAATC \\
PP017 & CCAAGGACACTTCTAGTCCTTC & CAGGAAGACTCCAGAACTGTGC \\
PP018 & CAGTTAGATGAGCCTGAGGAC & CGAGCCATTGCCCCAAGTTTG \\
PP020 & GTTGTTGGAATCGGGTAGAGG & GGTCTGATCTAACAGGATCCAG \\
PP021 & CACCCTCATGTGCTTCTTAATTC & CTTGAACAGAGTCATTTTTCTC \\
PP022 & GCGCAGCCCTAACTACAATAC & CAACGGCAAAAGACCTAGGTAC \\
PP023 & TGGGTCATCAGAGCTTTCAG & CAGCAGGTTAGTTCTGCACAGC \\
\hline
\end{tabular}


Entre as seis populações de $P$. pachyrhizi obtidas das cultivares suscetíveis, não foi observada variabilidade nos locos avaliados, o que indica que todas as populações pertencem ao mesmo isolado do patógeno. Portanto, há ausência de variabilidade entre essas populações. Desse resultado, pode-se inferir que não ocorreu pressão de seleção para o patógeno nessas cultivares de soja. A cultivar FT 2 foi descrita como resistente em 2002, quando a ferrugem-asiática-da-soja foi relatada pela primeira vez no Brasil. Contudo, no ano seguinte, esta resistência foi quebrada. Essa cultivar apresenta o gene denominado Rpp (FT2) (Yamanaka et al., 2008). No entanto, não houve variabilidade entre os isolados que esporularam nesta cultivar e os que esporularam nas outras cultivares, que não apresentavam genes de resistência.

Observou-se variabilidade genética entre as dez populações de $P$. pachyrhizi coletadas em diferentes regiões do Brasil. Dos 17 pares de iniciadores microssatélites utilizados para análise da variabilidade genética entre essas populações, 16 amplificaram $(94,11 \%)$ e $7(43,75 \%)$ foram polimórficos. As distâncias genéticas variaram de 0 a 0,36 , com média de 0,15 . Os valores mais frequentes de distância genética ficaram entre 0,10 e 0,25 (Figura 2). Não foi observada variação entre as populações de esporos coletadas em Palmital, SP; Rio Verde, GO; e Conceição das Alagoas, MG. As maiores distâncias foram obtidas entre as populações coletadas em Cascavel, PR, em 2010 (CVL2), e as populações coletadas em Rio Verde, GO; Conceição das Alagoas, MG; Palmital, SP; e São Miguel do Passa Quatro, MG.

Com o uso do método de agrupamento UPGMA, foi possível observar a formação de quatro grupos, ao

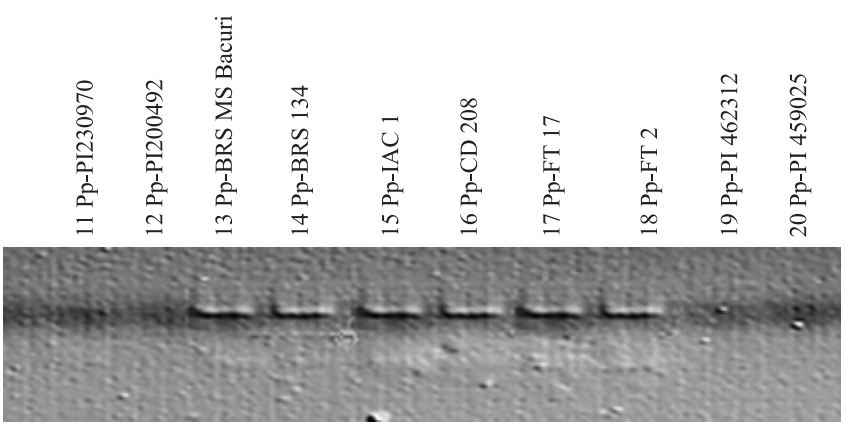

Figura 1. Amplificação das amostras obtidas de lesões "reddish-brown" (RB) e de populações de esporos de Phakopsora pachyrhizi coletadas sobre cultivares de soja suscetíveis. se utilizar a distância arbitrária de 0,13 como ponto de corte (Figura 3). O primeiro foi formado pelas populações coletadas em: Palmital, SP; Rio Verde, GO; Conceição das Alagoas, MG; e Ponta Porã, MS. O segundo grupo apresentou apenas uma população, coletada em Cascavel, PR, em 2009 (CVL1). No terceiro grupo, estão as populações coletadas em: São Miguel do Passa Quatro, MG; Santa Rosa, RS; Guarapuava, PR; e Campo Mourão, PR. O quarto grupo também foi formado por apenas uma população, coletada em Cascavel, em 2010 (CVL2). Houve tendência de as populações coletadas na região Centro Oeste do Brasil formarem um grupo distinto das populações coletadas no Sul, embora a população coletada em: São Miguel do Passa Quatro, MG, tenha sido agrupada com as populações do Sul. As duas populações coletadas em Cascavel foram as mais divergentes de todas.

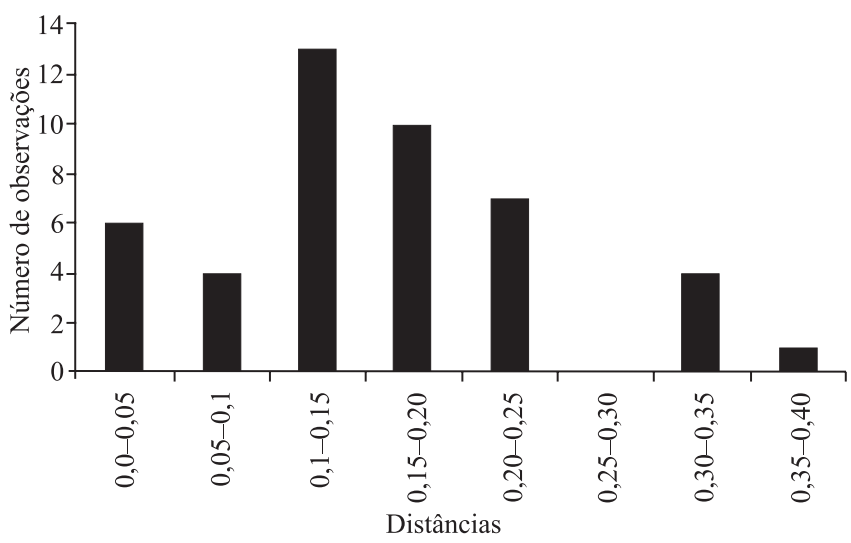

Figura 2. Distribuição de frequência das distâncias genéticas encontradas nas populações de esporos de Phakopsora pachyrhizi, coletadas em diversas regiões do Brasil.

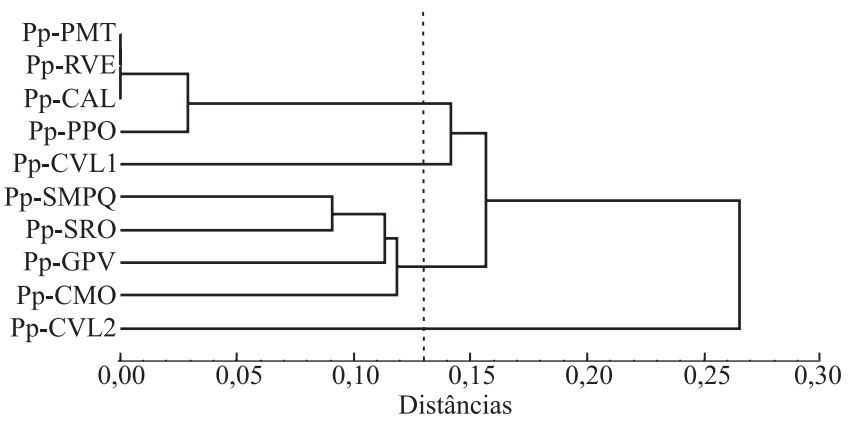

Figura 3. Agrupamento pelo método UPGMA entre as populações de esporos de Phakopsora pachyrhizi coletadas em diversas regiões do Brasil, nas safras 2008/2009 e 2009/2010, a partir das distâncias genéticas obtidas por meio da análise com marcadores moleculares microssatélites. 
Freire et al. (2008), ao utilizar dados de sequências de regiões ITS, concluíram que há diferentes introduções do fungo no Brasil, o que justifica a variabilidade encontrada no patógeno.

A análise de agrupamento pelo método UPGMA apresentou correlação cofenética de 0,84 com os dados originais, o que indica que o agrupamento obtido representa estes dados.

A variabilidade genética em populações de $P$. pachyrhizi tem sido relatada de acordo com a variabilidade na virulência do patógeno (Sinclair \& Hartman, 1999; Yamaoka et al., 2002; Bonde et al., 2006) e por análise molecular de regiões ITS (Freire et al. 2008). Anderson et al. (2008), ao utilizar o mesmo conjunto de marcadores microssatélites do presente trabalho, avaliaram sua informatividade em isolados de $P$. pachyrhizi coletados em diferentes países. Este é o primeiro relato da variabilidade de isolados de P. pachyrhizi obtida por marcadores microssatélites. Os resultados são indicativos de variabilidade genética entre os isolados. Porém, não é possível, a partir dos resultados obtidos, inferir sobre a variabilidade na patogenicidade dos isolados. No entanto, como há variabilidade genética a nível molecular, devese esperar que também ocorra variabilidade de patogenicidade quando os isolados forem submetidos à pressão de seleção pelo uso de cultivares resistentes. Observou-se variabilidade de resposta das fontes de resistência contendo os genes $R p p 2$ e $R p p 4$, quando receberam inoculação com diferentes isolados (Soares et al., 2008), o que mostra que há variabilidade na patogenicidade do fungo no Brasil.

Recentemente, no Brasil, diversos trabalhos têm sido realizados para se conhecer os mecanismos de resistência à ferrugem-asiática-da-soja, sejam estes qualitativos (Santos et al., 2007; Silva et al., 2007; Costa et al., 2008; Laperuta et al., 2008; Morceli et al., 2008) ou quantitativos (Koga et al., 2008; Ribeiro et al., 2009a, 2009b; Cruz et al., 2011). A associação de mecanismos qualitativos, por meio da piramidação de genes de resistência, e de mecanismos quantitativos, de resistência horizontal, deve ser utilizada como estratégia dos programas de melhoramento de soja, para que se possa obter resistência mais duradoura. A resistência baseada em genes únicos tende a ser quebrada, em virtude da variabilidade do patógeno.

No presente trabalho, houve variabilidade entre as populações de fungos coletadas em diferentes regiões do Brasil. Observou-se tendência de agrupamento dessas populações em grupos que representam a região Centro Oeste e a região Sul do país. A existência de variabilidade genética entre os isolados, ainda que não associada à variação na patogenicidade, é um alerta para que o desenvolvimento de cultivares resistentes seja baseado em mecanismos de resistência mais duradoura, seja pela resistência horizontal, seja pela piramidação de genes de resistência vertical.

\section{Conclusões}

1. Existe variabilidade genética, acessada por marcadores moleculares microssatélites, em populações de esporos do fungo Phakopsora pachyrhizi no Brasil.

2. Autilização de cultivares de soja com genes únicos de resistência vertical pode levar à rápida seleção de biótipos que quebrem a resistência dessas variedades.

\section{Referências}

ANDERSON, S.J.; STONE, C.L.; POSADA-BUITRAGO, M.L.; BOORE, J.L.; NEELAM, B.A.; STEPHENS, R.M.; LUSTER, D.G.; FREDERICK, R.D.; PEDLEY, K.F. Development of simple sequence repeat markers for the soybean rust fungus, Phakopsora pachyrhizi. Molecular Ecology Resources, v.8, p.1310-1312, 2008.

ANDRADE, P.J.M.; ANDRADE, D.F. de A.A. Ferrugem asiática: uma ameaça à sojicultura brasileira. Dourados: Embrapa Pecuária Oeste, 2002. 11p. (Embrapa Pecuária Oeste. Circular técnica, 11).

BONDE, M.R.; NESTER, S.E.; AUSTIN, C.N.; STONE, C.L.; FREDERICK, R.D.; HARTMAN, G.L.; MILES, M.R. Evaluation of virulence of Phakopsora pachyrhizi and P. meibomiae isolates. Plant Disease, v.90, p.708-716, 2006.

BROMFIELD, K.R. Disease management. In: BROMFIELD, K.R. Soybean rust. St. Paul: The American Phytopathological Society, 1984. p.43-49. (Monograph, 11).

BROMFIELD, K.R.; HARTWIG, E.E. Resistance to soybean rust and mode of inheritance. Crop Science, v.20, p.254-255, 1980.

CHENG, Y.W.; CHAN, K.L. The breeding of rust resistant soybean Tainung 3. Journal of Taiwan Agricultural Research, v.17, p.30-34, 1968.

COSTA, M.M.; UNÊDA-TREVISOLI, S.H.; PINHEIRO, J.B.; KIIHL, R.A. de S.; CALVO, É.S.; DI MAURO, A.O. Marcadores RAPD para detecção de resistência à ferrugem-asiática-da-soja. Pesquisa Agropecuária Brasileira, v.43, p.1733-1739, 2008.

CRUZ, C.D. Programa Genes: aplicativo computacional em genética e estatística: versão Windows. Viçosa: UFV, 2001. $648 \mathrm{p}$.

CRUZ, M.F.A. da; SOUZA, G.A. de; RODRIGUES, F.Á.; SEDIYAMA, C.S.; BARROS, E.G. de. Reação de genótipos de soja à infecção natural por ferrugem asiática. Pesquisa Agropecuária Brasileira, v.46, p.215-218, 2011. 
FREIRE, M.C.M.; OLIVEIRA, L.O. de; ALMEIDA, A.M.R. de; SCHUSTER, I.; MOREIRA, M.A.; LIEBENBERG, M.M.; MIENIE, C.M.S. Evolutionary history of Phakopsora pachyrhizi (the Asian soybean rust) in Brazil based on nucleotide sequences of the internal transcribed spacer region of the nuclear ribosomal DNA. Genetics and Molecular Biology, v.31, p.920-931, 2008.

GARCIA, A.; CALVO, É.S.; KIIHL, R.A. de S.; HARADA, A.; HIROMOTO, D.M.; VIEIRA, L.G.E. Molecular mapping of soybean (Phakopsora pachyrhizi) resistance genes: discovery of novel locus and alleles. Theoretical and Applied Genetics, v.117, p.545-553, 2008.

HARTWIG, E.E. Identification of a fourth major gene conferring resistance to soybean rust. Crop Science, v.26, p.1135-1136, 1985.

HARTWIG, E.E.; BROMFIELD, K.R. Relationships among three genes conferring specific resistance to rust in soybeans. Crop Science, v.23, p.237-239, 1982.

HIDAYAT, O.O.; SOMAATMADJA, S. Screening of soybean breeding lines for resistance to soybean rust (Phakopsora pachyrhizi Sydow). Soybean Rust Newsletter, v.1, p.9-22, 1977.

KOGA, L.J.; CANTERI, M.G.; CALCO, É.S.; UNFRIED, J.R.; GARCIA, A.; HARADA, A.; KIIHL, R.A. de S. Análise multivariada dos componentes da resistência à ferrugem-asiática em genótipos de soja. Pesquisa Agropecuária Brasileira, v.43, p.1277-1286, 2008.

LAPERUTA, L. Di C.; ARIAS, C.A.A.; RIBEIRO, A.S.; RACHID, B.F.; PIEROZZI, P.H.B.; TOLEDO, J.F.F. de; PÍPOLO, A.E.; CARNEIRO, G.E. de S. New genes conferring resistance to Asian soybean rust: allelic testing for the Rpp2 and Rpp4 loci. Pesquisa Agropecuária Brasileira, v.43, p.1741-1747, 2008.

MCLEAN, R.J.; BYTH, D.E. Inheritance of resistance to rust (Phakopsora pachyrhizi) in soybeans. Australian Journal of Agricultural Research, v.31 p.951-956, 1980.

MILES, M.R.; FREDERICK, R.D.; HARTMAN, G.L. Evaluation of soybean germplasm for resistance to Phakopsora pachyrhizi. Plant Health Progress, 2006. Doi:10.1094/PHP-2006-0104-01-RS.

MORCELI, T.G.S.; UNÊDA-TREVISOLI, S.H.; MORCELI JUNIOR, A.A.; KIIHL, R.A. de S.; CALVO, É.S.; DI MAURO, A.O.; GARCIA, A. Identificação e validação de marcadores microssatélites ligados ao gene $R p p 5$ de resistência à ferrugem-asiática-da-soja. Pesquisa Agropecuária Brasileira, v.43, p.1533-1541, 2008.

RIBEIRO, A.S.; TOLEDO, J.F.F. de; RAMALHO, M.A.P. Interference of genotypes $\mathrm{x}$ environments interaction in the genetic control of resistance to Asian rust soybean. Pesquisa Agropecuária Brasileira, v.44, p.1160-1167, 2009a.

RIBEIRO, A.S.; TOLEDO, J.F.F. de; RAMALHO, M.A.P. Selection strategies of segregant soybean populations for resistance to Asian rust. Pesquisa Agropecuária Brasileira, v.44, p.1452-1459, 2009b.
ROEDER, V.; BRODA, P. Rapid preparation of DNA from filamentous fungi. Letters in Applied Microbiology, v.1, p.17-20, 1987.

SANTOS, J.A.; JULIATTI, F.C.; SANTOS, V.A.; POLIZEL, A.C.; JULIATTI, F.C; HAMAWAKI, O.T. Caracteres epidemiológicos e uso da análise de agrupamento para resistência parcial à ferrugem da soja. Pesquisa Agropecuária Brasileira, v.42, p.443-447. 2007.

SCHNEIDER, R.W.; HOLLIER, C.A.; WHITAM, H.K.; PALM, M.E.; MCKEMY, J.M.; HERNANDEZ, J.R.; LEVY, L.; DEVRIES-PATERSON, R. First report of soybean rust caused by Phakopsora pachyrhizi in the continental United States. Plant Disease, v.89, p.774, 2005.

SILVA, V.A.S.; JULIATTI, F.C.; SILVA, L.A.S. Interação entre resistência genética parcial e fungicidas no controle da ferrugem asiática da soja. Pesquisa Agropecuária Brasileira, v.42, p.1261-1268, 2007.

SINCLAIR, J.B.; HARTMAN, G.L. Soybean rust. In: HARTMAN, G.L.; SINCLAIR, J.B.; RUPE, J.C. (Ed.). Compendium of soybean diseases. 4.ed. St. Paul: American Phytopathological Society, 1999. p.25-26.

SINGH, B.B.; THAPLIYAL, P.N. Breeding for resistance to soybean rust in India. In: FORD, R.E.; SINCLAIR, J.B. (Ed.). Rust of soybean: the problem and research needs. Urbana: University of Illinois, 1977. p.62-65. (INTSOY. Series, 12).

SOARES, R.M.; AKAMATSU, H.; YAMANAKA, N.; SUENAGA, K.; YAMAOKA,Y.; IVACOVICH, A.; MOREL, W.; JANEGITZ, T. Variabilidade patogênica do fungo Phakopsora pachyrhizi. Parte I - projeto ferrugem da soja JIRCAS/Embrapa Soja/ CRIA/ INTA/Tsukuba University. In: REUNIÃO DO CONSÓRCIO ANTIFERRUGEM SAFRA 2008/2009, 2009, Londrina. Resumos. Londrina: Embrapa Soja, 2009. p.93-101. (Embrapa Soja. Documentos 315).

STASOFT. STATISTICA for Windows: computer program manual. 1999. Available at: <http://www.statsoft.com $>$. Accessed on: 14 Feb. 2012.

TECNOLOGIAS de produção de soja - região central do Brasil 2004. Londrina: Embrapa Soja, 2003. 237p. (Embrapa Soja. Sistemas de produção, 4).

YAMANAKA, N.; SILVA, D.C.G.; PASSIANOTO, A.L.L.; NOGUEIRA, L.M.; POLIZEL, A.M.; PEREIRA, R.M.; SANTOS, J.V.M.; BROGIN, R.L.; ARIAS, C.A.A.; HOFFMANN-CAMPO, C.B.; NEPOMUCENO, A.L.; ABDELNOOR, R.V. Identification of DNA markers and characterization of the genes for resistance against Asian soybean rust. JIRCAS Working Report, v.58, p.99-107, 2008.

YAMAOKA, Y.; FUJIWARA, Y.; KAKISHIMA, M.; KATSUYA, K.; YAMADA, K.; HAGIWARA, H.I. Pathogenic races of Phakopsora pachyrhizi on soybean and wild host plants collected in Japan. Journal of General Plant Pathology, v.68, p.52-56, 2002 . 